\title{
ESTUDO DO EFEITO DE ALGUMAS VARIÁVEIS DE FABRICAÇÃO NO PERFIL TEXTUROMÉTRICO DO DOCE DE MANGA ${ }^{1}$
}

\author{
Acir Moreno SOARES JUNIOR ${ }^{2}$, Amazile Biagioni Ribeiro de Abreu MAIA², David Lee NELSON,*
}

\begin{abstract}
RESUMO
A fim de elaborar um doce de manga em massa com excedentes de produção, foi iniciado o estudo de parâmetros físico-químicos da manga, variedade "coquinho" e do doce obtido dessa manga, empregando-se diversas formulações. Primeiramente, foi determinada a composição da manga madura e o efeito da variação do teor de polpa, de sólidos totais e de ácido cítrico na consistência do gel obtido. Foram testadas formulações variando quatro parâmetros: teores de pectina e de ácido cítrico adicionados, proporção entre polpa e açúcar na mistura inicial e concentração de sólidos no produto final. A textura foi avaliada usando um texturômetro. O teor de pectina requerido foi da ordem de $1 \%$ sobre o peso do produto final. A adição de ácido cítrico deve ser mantida na faixa entre 0,6 e $1,0 \%$. Acima de $1 \%$ a textura do produto ficou prejudicada pelo efeito de hidrólise da pectina. Abaixo de $0,6 \%$, a inversão do açúcar pode ser insuficiente para estabilizar a textura, acarretando a formação de cristais durante o armazenamento que comprometem a qualidade do doce. O incremento do teor de sólidos solúveis aumenta a dureza do produto, e um tempo de cozimento elevado pode acarretar uma hidrólise excessiva da pectina, resultando na não formação do gel.

Palavras-chave: doce de manga; textura; parâmetros fisico-quimicos.
\end{abstract}

\section{SUMMARY}

THE STUDY OF SOME PRODUCTION VARIABLES ON THE TEXTUROMETRIC PROFILE OF MANGO PRESERVES. To produce a mango preserve sufficiently consistent for cutting, utilizing production surpluses, the study of physical-chemical parameters of the mango variety "coquinho" and of the preserve obtained from that mango with variations of certain parameters was initiated. Firstly, the composition of the mature mango and the effect of the variation in pulp content, total solids and citric acid concentration on the consistency of the gel obtained was determined. Formulations were tested varying four parameters: contents of pectin and of added citric acid, proportion between pulp and sugar in the initial mixture and concentralion of solids in the final product. The texture was evaluated using a texturometer. the content of pectin required was on the order of $1 \%$ based on the weight of the final product. The addition of citric acid should be maintained in the range between 0.6 and $1.0 \%$. Above $1.0 \%$ hydrolysis of the pectin occurs in detriment to the texture of the product. Below $0.6 \%$, the inversion of the sugar can be insufficient to stabilize the texture, leading to formation of crystals during storage. The increase in the soluble solids content increases the hardness of the product, but an extended cooking time may lead to an excessive hydrolysis of the pectin, resulting in no gel formation.

Keywords: mango preserves; texture; physical-chemical parameters.

\section{1 - INTRODUÇÃO}

Como a maioria das frutas tropicais, a manga é produzida em grande quantidade durante um período curto de tempo (dezembro a fevereiro) e, devido à sua alta perecibilidade, deteriora-se rapidamente [3, 8]. Apesar do grande desenvolvimento das técnicas de preservação pós-colheita, ainda não se conseguiu nenhuma adequada e economicamente viável para atender ao volume de produção dessa fruta [10]. Dessa forma, acumulam-se as perdas de excedentes de produção e de descartes inadequados à comercialização ao natural, com grandes prejuizos, especialmente para os pequenos produtores que não conseguem levar o seu produto até os grandes centros comerciais. Assim sendo, faz-se necessário disponibilizar opções para a conservação da manga que associem simplicidade tecnológica, baixos custos de embalagem e acondicionamento, facilidade de transporte e, ainda, boa aceitação no mercado. Neste sentido, a

\footnotetext{
1. Recebido para publicação em 26/06/2001. Aceito para publicação em 15/05/2002.

2. Departamento de Alimentos, FAFAR, Universidade Federal de Minas Gerais, Av. Olegário Maciel, 2360, Lourdes, CEP 30180-112-Belo Horizonte-MG. E-mail: dinufmg@dedalus.lcc.ufmg.br

3. Centro Universitário de Belo Horizonte, Departamento de Ciências Biológics e da Saúde, Av. Mário Werneck, 1685, CEP 31110-320 - Belo Horizonte-MG * A quem a correspondência deve ser enviada.
}

possibilidade de elaborar o doce de manga em massa, destinado a corte e embalado em barrinhas de 25 a $50 \mathrm{~g}$, torna-se especialmente atraente. A produção de doce de manga em massa é uma atividade artesanal de grande tradição no estado de Minas Gerais. Contudo, as técnicas empregadas ainda não propiciam um grau de padronização satisfatório ao produto, que freqüentemente apresenta deficiências relacionadas à acidez, dureza, adesividade à lâmina de corte, sinérese e outros. O objetivo deste trabalho foi estabelecer referenciais para a padronização do doce de manga, assegurando a textura adequada para o corte.

\section{2 - MATERIAL E MÉTODOS}

Foram empregadas mangas maduras da variedade "coquinho" em estádio avançado de maturação, presumivelmente equivalente ao dos descartes de comercialização, conforme identificado pela cor da casca e da polpa e pelo aroma. Os ingredientes usados foram açúcar tipo cristal, ácido cítrico de grau alimentício e pectina de alto grau de metoxilação (Braspectina, tipo $8105, \mathrm{DM}>50 \%)$. As mangas foram descascadas manualmente, removendo-se os caroços com auxílio de facas de aço inoxidável. A polpa foi processada em liquidificador e peneirada para remoção das fibras. Os doces foram elaborados em uma panela elétrica dotada de camisa de vapor e com sistema de agitação manual. Cada 
amostra preparada correspondia a cerca de $600 \mathrm{~g}$ de doce, acondicionados em potes de polietileno opacos, providos de tampa e com capacidade para $150 \mathrm{~g}$.

Foram efetuadas as seguintes análises, conforme IAL [6]: sólidos solúveis, por gravimetria; acidez titulável, por titulação com solução de $\mathrm{NaOH}$ em presença de fenolftaleína; $\mathrm{pH}$, por potenciometria; açúcares redutores e totais, por titulometria com o reagente de Fehling. Para avaliação da textura, usou-se o texturômetro TAXT2 da Stable Micro System com uma sonda cilíndrica de aço inóx $(\phi=4 \mathrm{~mm})$ e inicializado com os seguintes parâmetros: Test mode $=$ Measure force in compression; Test option $=$ Cycle until count; Test speed $=1 \mathrm{~mm} / \mathrm{S} ;$ Distance $=20,0 \mathrm{~mm} ;$ Count $=1$; Trigger $=5 \mathrm{~g}$. As análises foram feitas em triplicata. Cada polpa analisada foi obtida a partir de aproximadamente 50 frutos.

Foram feitos alguns testes preliminares sem adição de pectina, variando o teor de polpa de $45 \%$ a $75 \%$, o teor de sólidos totais no doce de 68 a $74 \%$ e o teor de ácido cítrico até alcançar $\mathrm{pH}$ 3,0. Nos ensaios subseqüentes, com adição de pectina comercial, foram testadas variações nos teores de pectina e de ácido cítrico adicionados, na proporção inicial entre polpa e açúcar e na concentração final de sólidos solúveis.

A partir dos perfis de textura das formulações elaboradas com adição de pectina, foram avaliados os seguintes parâmetros no produto resultante: (a) dureza inicial - força de resistência máxima oferecida pela amostra antes da ruptura da superficie do gel. (b) energia para a remoção da sonda. Esta energia está relacionada às forças cisalhantes atuando na superfície da sonda, as quais são determinadas pela adesividade da amostra. Empregou-se um delineamento fatorial $2^{\mathrm{k}} \mathrm{com}$ a adição de pontos centrais para o estudo simultâneo das variáveis [4, 9].

\section{3 - RESULTADOS E DISCUSSÃo}

\section{1- Testes preliminares}

O peso médio e as características da polpa do lote de mangas usado nos estudos encontram-se na Tabela 1.

TABELA 1. Peso médio e características médias da polpa de manga madura, variedade Coquinho

\begin{tabular}{llcc}
\hline Parâmetro & Unidade & Média & Desvio padrão \\
\hline Peso médio do fruto & $\mathrm{g}$ & 110,0 & 24,8 \\
Sólidos totais & $\mathrm{g} / 100 \mathrm{~g}$ & 14,4 & 0,06 \\
Sólidos insolúveis & $\mathrm{g} / 100 \mathrm{~g}$ & 1,0 & 0,10 \\
$\mathrm{pH}$ & - & 3,67 & 0,03 \\
Acidez & $\mathrm{g}$ ác. cítrico/100g & 0,8 & 0,02 \\
Açúcares redutores & $\mathrm{g}$ glicose $/ 100 \mathrm{~g}$ & 5,1 & 0,15 \\
Açúcares não redutores & $\mathrm{g}$ sacarose $/ 100 \mathrm{~g}$ & 6,5 & 0,21 \\
Açúcares totais & $\mathrm{g}$ glicose $/ 100 \mathrm{~g}$ & 12,0 & 0,35 \\
Pectina & $\mathrm{g} / 100 \mathrm{~g}$ & 0,9 & 0,01
\end{tabular}

Nenhuma das formulações preliminares, sem adição de pectina, permitiu obter um gel consistente, inviabilizando a obtenção dos perfis texturométricos [11]. Partiu-se, então, para testes com emprego de agente geleificante.

\section{2 - Testes com adição de pectina}

Os resultados analíticos encontram-se na Tabela 2. Conforme delineamento fatorial, foram testadas 16 formulações (amostras 1 a 16) com 3 repetições (amostras de 17 a 19).

TABELA 2. Formulações com adição de pectina para o doce de manga e resultados analíticos

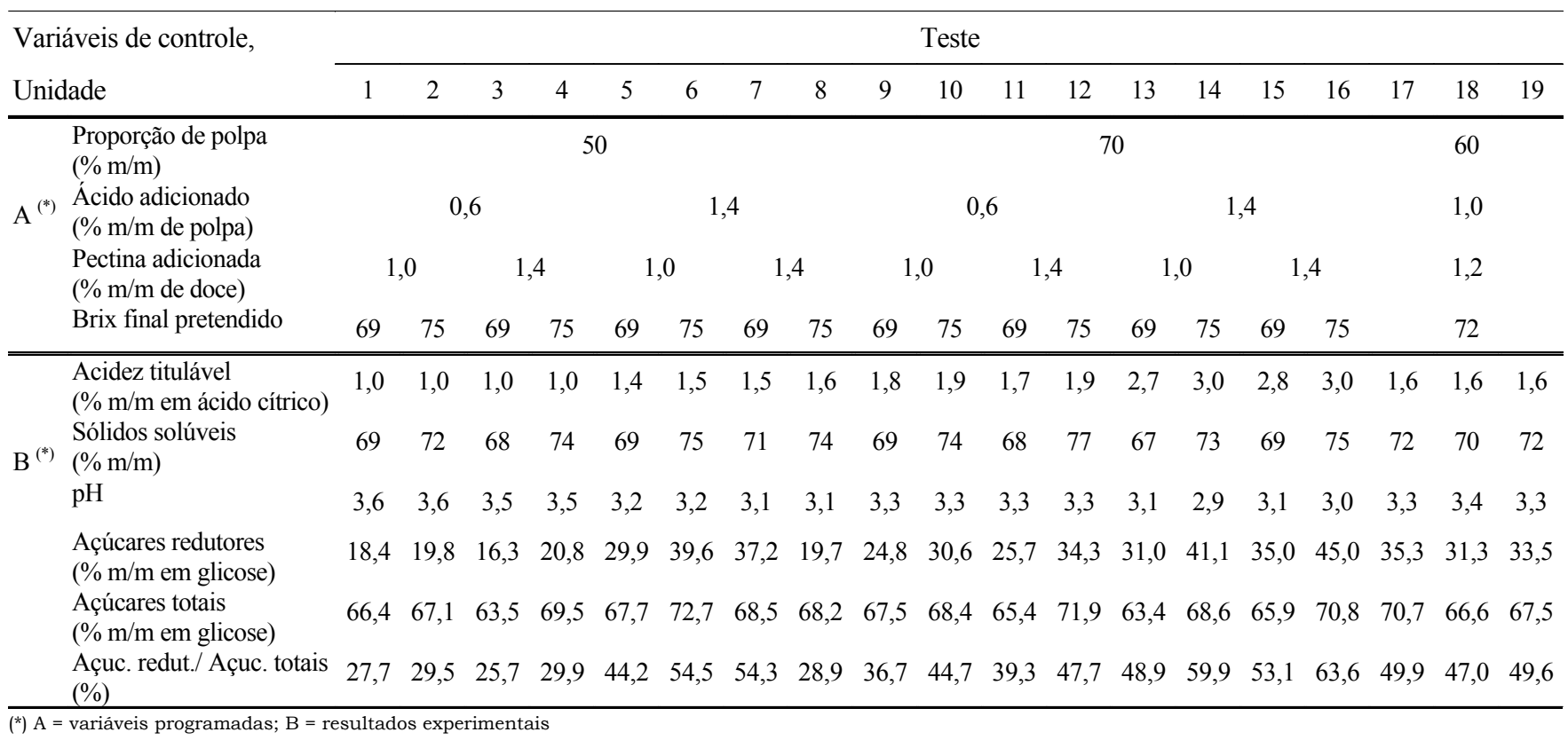




\section{3 - Efeito do teor final de sólidos solúveis}

O aumento do teor de sólidos solúveis afeta a textura do doce de duas maneiras. Por um lado, a redução do teor de água aumenta a rigidez da estrutura [5]. Por outro, a necessidade de evaporar uma quantidade maior da água da massa acarreta, necessariamente, aumento no tempo de cozimento e na temperatura da massa. Com isso, aumentam as chances de hidrólise da pectina, o que torna a estrutura descontínua e mais aderente [1, 7]. A extensão de hidrólise da pectina é potencializada pelo aumento da concentração de ácido [7]. A ocorrência desses dois fenômenos pode ser observada pela comparação dos perfis texturométricos dos pares de amostras 05-06 e 15-16 (Figura 1). Em cada par apresentado, a única variável distinta foi o teor de sólidos totais (Tabela 2). No primeiro caso (Figura 1-A), empregando-se um teor
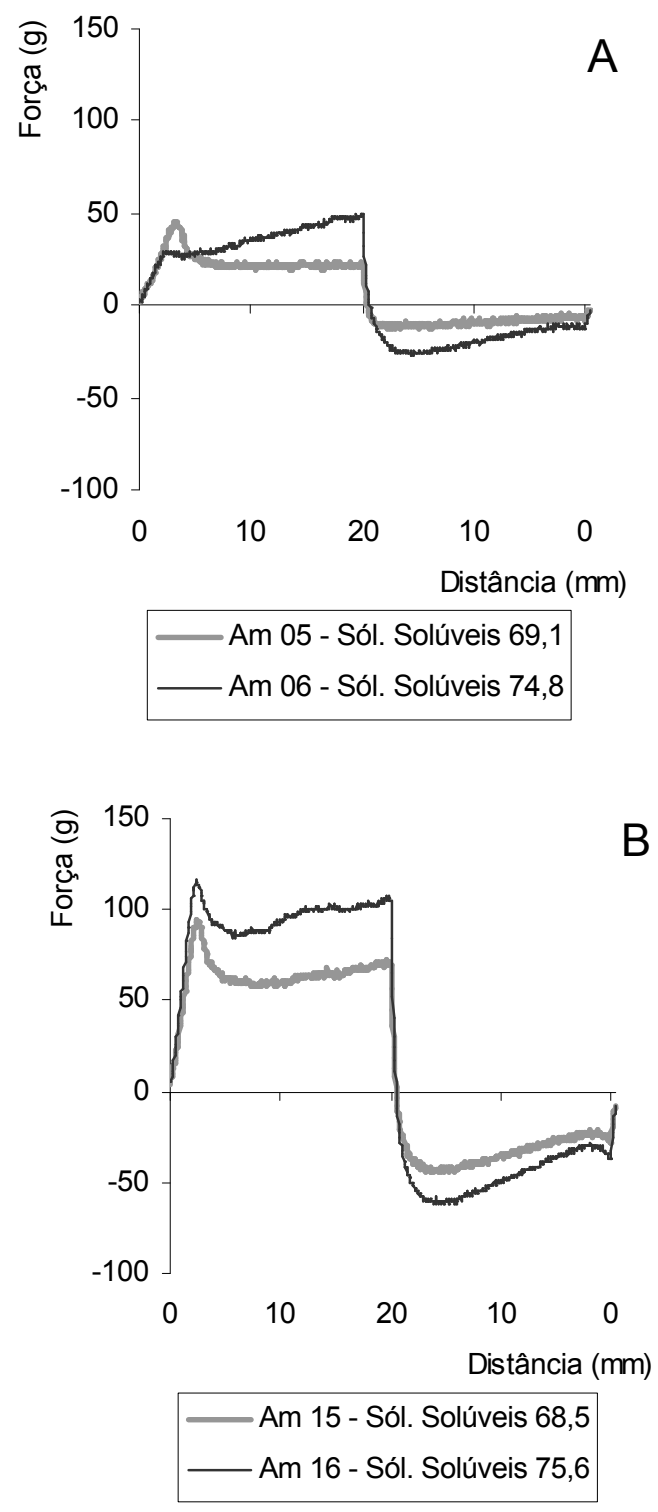

FIGURA 1. Perfis texturométricos de pares de amostras com a mesma formulação e teores de sólidos solúveis diferentes. de ácido elevado e teores de polpa e de pectina reduzidos, com o aumento do teor de sólidos solúveis, observa-se o desaparecimento do pico de força inicial, evidenciando a perda da continuidade da estrutura tridimensional característica do gel. No segundo par (Figura 1-B), empregando-se teores de polpa e pectina mais elevados, com o aumento do teor de sólidos solúveis, verifica-se um aumento da rigidez da estrutura sem uma alteração significativa da continuidade do gel, evidenciada pelo aumento proporcional da força de penetração da sonda [2]. Observa-se ainda, de uma forma geral, um aumento da adesividade resultante do aumento do teor de sólidos solúveis, conforme se deduz pelo aumento da energia de remoção da sonda [11].

\section{4 - Efeito do teor de polpa adicionado}

O aumento do teor de polpa eleva a concentração da pectina proveniente do fruto no produto final. Com isso, sempre que o teor de polpa foi aumentado, mantendo-se as demais variáveis constantes, independentemente dos valores empregados para essas, obteve-se um produto com maior dureza, fato evidenciado pelo aumento da força de resistência à penetração da sonda [12]. Observa-se também que, com o aumento do teor de polpa, ocorreu a formação do gel em todas as condições testadas, exceto quando se empregou um teor baixo de pectina associado a uma elevada concentração de ácido e de sólidos solúveis (Figura 2), onde não se observou um pico de força pronunciado característico do gel. Portanto, o aumento do teor de polpa na formulação resulta em uma redução das quantidades necessárias de ácido, pectina e açúcar, podendo reduzir o custo de produção.

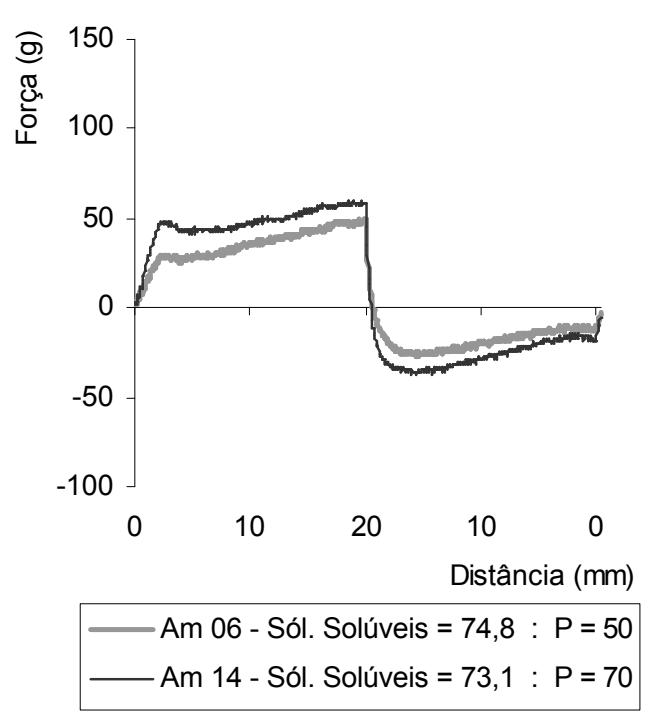

FIGURA 2. Perfis texturométricos das amostras 06 e14.

\section{5 - Efeito do teor de ácido adicionado}

Comparando as amostras 01 e 05, observa-se que a concentração mais elevada de ácido propiciou aumento da dureza do gel na amostra 05, contendo baixa concen- 
tração de sólidos solúveis, de polpa e de pectina (Figura 3A). Esse fato pode ser atribuído à menor dissociação das carboxilas livres nas moléculas de pectina, o que diminui a repulsão intermolecular e favorece formação de ligações cruzadas, essenciais para formação do gel [1,5]. Já entre as amostras 10 e 14 (Figura 3-B), o aumento da concentração de ácido promoveu um efeito contrário ao anterior em relação à consistência do doce. Esse fato, evidenciado pelo desaparecimento do pico de força inicial na amostra 14, foi atribuído ao favorecimento da hidrólise da pectina pelo ácido, resultando em uma estrutura de gel descontinua ou simplesmente mais frágil [7].
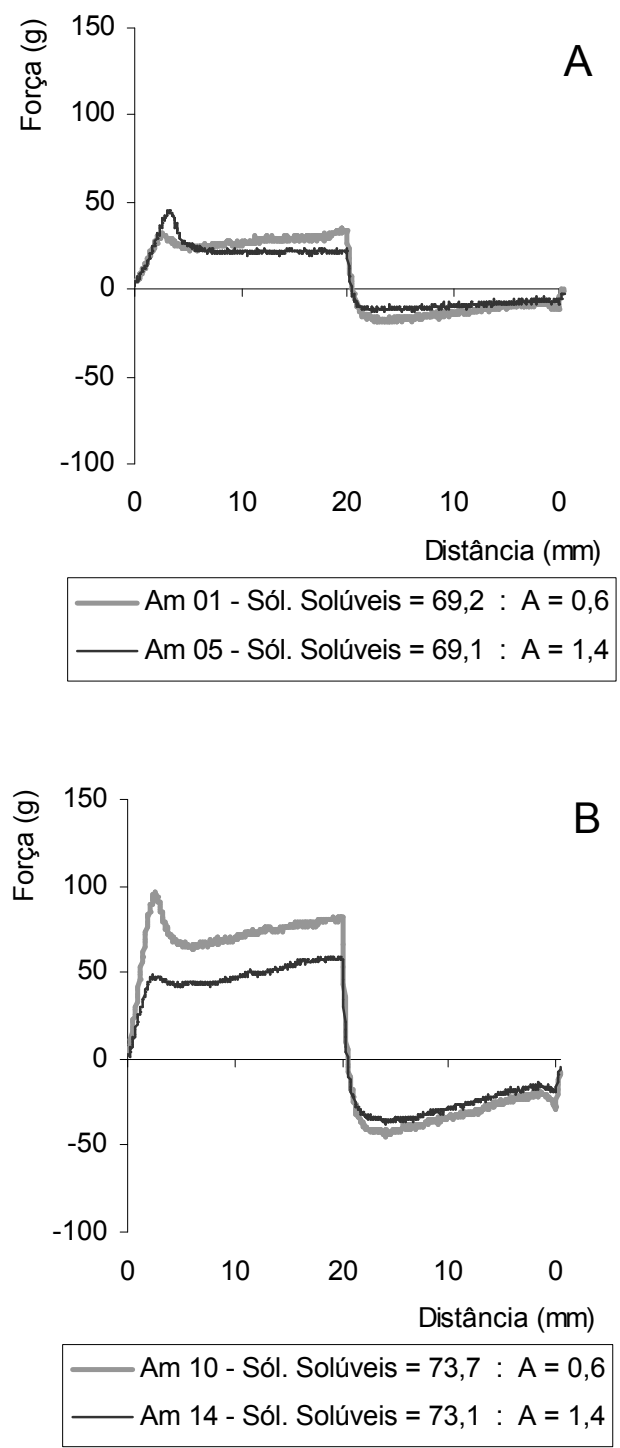

FIGURA 3. Perfis texturométricos de pares de amostras com Brix, teor de polpa e de pectina iguais e teor de ácido diferente.

\section{6 - Efeito do teor de pectina adicionado}

De forma geral, o aumento do teor de pectina resultou no aumento da dureza das amostras. Observou-se tanto a formação de uma estrutura de gel rígida com concentrações menores de pectina (1\%) (Figura 4-A) como a obtenção de estruturas descontínuas com concentrações elevadas de pectina (Figura 4-B). Dessa forma, verificamos que o teor minimo de pectina ( 1\%) para a formação de um gel $[1,7]$ pode ser reduzido ou aumentado em função das demais variáveis de processo.
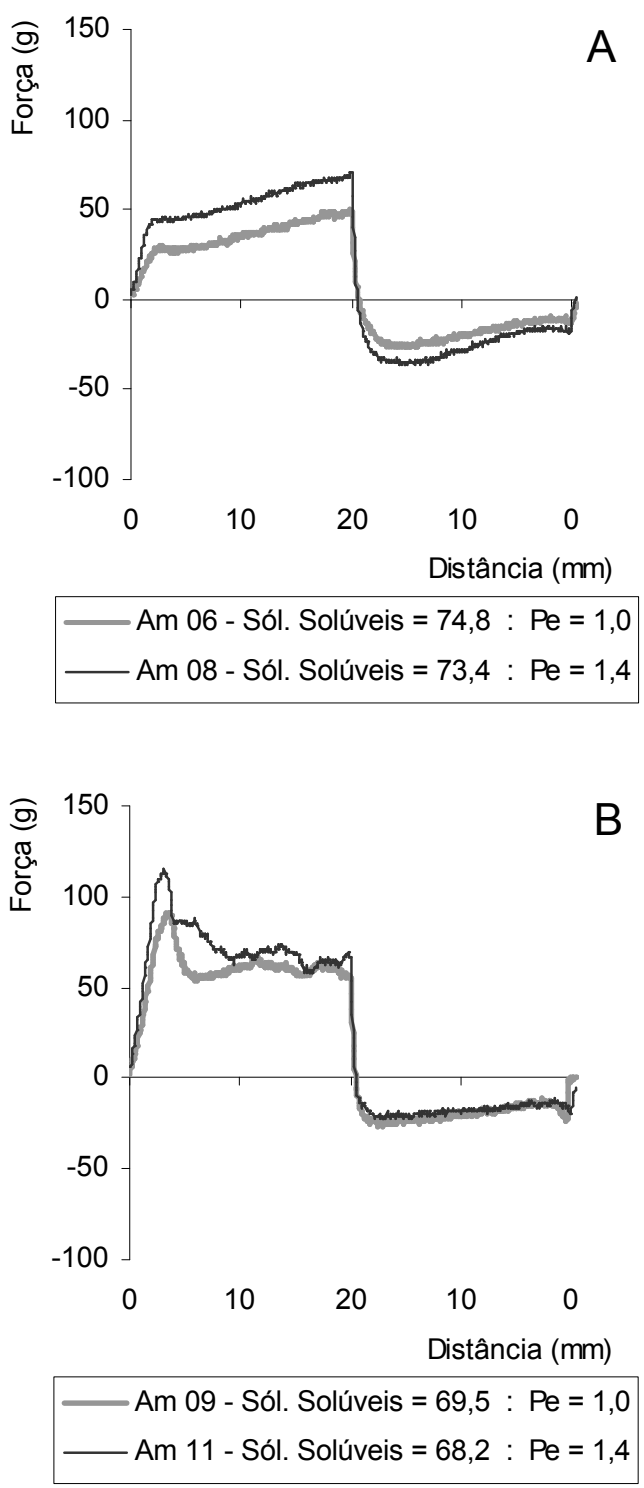

FIGURA 4. Perfis texturométricos de pares de amostras com Brix, teor de polpa e de ácido iguais e teor de pectina diferente.

\section{7 - Cristalização}

Durante a estocagem das amostras, observou-se que algumas delas (as de número 1, 2, 3, 4 e 8) cristalizaram espontaneamente após 6 a 8 dias. Em todas as amostras que cristalizaram, a proporção entre açúcares redutores e totais foi inferior a 30\%. Nas demais amostras, em que não ocorreu cristalização do açúcar, a referida proporção foi superior a 35\%. Esses resultados corrobo- 
ram trabalho anterior de JACKIX [7] que apontou a necessidade de um percentual mínimo de $24 \%$ de açúcares redutores para que não ocorra cristalização.

\section{4 - CONCLUSÕES}

O estudo evidenciou a necessidade de adição de pectina para a obtenção do doce com textura adequada para corte a partir da manga madura (variedade coquinho). O teor requerido é da ordem de $1 \%$ sobre o peso do produto final, podendo ser ainda mais alto se as condições do processamento forem favoráveis à hidrólise. Isso ocorre, por exemplo, quando o cozimento é excessivamente lento ou em presença de teor elevado de ácido. Pelos testes efetuados, a adição de ácido cítrico deve ser mantida na faixa entre 0,6 e $1,0 \%$. Acima de $1,0 \%$ a textura do produto já fica prejudicada pelo efeito de hidrólise da pectina. Abaixo de $0,6 \%$, a inversão do açúcar pode ser insuficiente para estabilizar a textura, acarretando formação de cristais durante o armazenamento que comprometem a qualidade do doce. O aumento do teor de sólidos solúveis aumenta a dureza do produto, porém um tempo de cozimento elevado pode acarretar uma hidrólise excessiva da pectina, resultando na não formação do gel.

\section{5 - REFERÊNCIAS}

[1] ALIKOnIS, J. J. Starch and pectin jellies. In: Candy Technology. Connecticut: AVI, 1979. Cap. 10. p. 10918.

[2] BELLARDE, F. B. Utilização de alginato de sódio na produção de um gel estruturado de suco de maracujá (Passiflora edulis S.). Campinas: UNICAMP, 1995. 60p. (Dissertação, Mestrado em Tecnologia de Alimentos).

[3] BRINSON, K., DEY, P. M., JOHN, M. A., PRIDHAM, J. B. Post-harvest changes in Mangifera indica mesocarp cell walls and cytoplasmatic polysaccharides. Phytochemistry, v. 27, n. 3, p. 719-23, 1988.
[4] ENNIS, D. M., BOELENS, H., HARING, H., BOWMAN, P. Multivariate analysis in sensory evaluation. Food Technol., v. 36, n. 11 , p. 83-90, 1982.

[5] GLICKSMAN, M. Gum technology in the food Industry. New York: Academic Press, 1969. Cap. 6. Pectins. p. 15989.

[6] IAL - Instituto Adolfo Lutz - Normas Analíticas do Instituto Adolf Lutz. São Paulo: IAL, 1985. v. 1. caps. 4 e 13.

[7] JACKIX, M. H. Doces, geléias e frutas em calda. Campinas: Ícone, 1988. $172 \mathrm{p}$.

[8] KANE, J. K. Marketing mango products. Food Australia, v. 43, n. 3, p. 111-2, 1991.

[9] MONTGOMERY, D. C., RUNGER, G. C. Applied statistics and probability for engineers. 5. ed. New York: John Wiley, 1994. p.531-801.

[10] NWANEKEZI, E. C., ALAWUBA, O. C. G., MKPOLUlu, C. C. M. Characterization of pectic substances from selected tropical fruits. J. Food Sci. Technol., v. 31, n. 2, p. 159-61, 1994.

[11] SOARES JR, A. M. Efeito de alguns parâmetros de produção sobre as características reológicas do doce de manga (Mangifera indica L.). Belo Horizonte:Escola de Farmácia-UFMG, 2000. 67 p. (Dissertação, Mestrado em Ciência de Alimentos).

[12] SOUZA, S. J. F. Estudo comparativo de onze variedades de manga (mangifera indica L.), produzidas em Visconde do Rio Branco, Minas Gerais, visando ao consumo natural e à elaboração de geléias. Viçosa: UFV, 1983. 57 p. (Dissertação, Mestrado em Ciência e Tecnologia de Alimentos).

\section{6 - AGRADECIMENTOS}

Apoio financeiro foi fornecido pela Fundação de Amparo de Pesquisa do Estado de Minas Gerais - FAPEMIG. Dr. D.L.Nelson recebeu uma bolsa de produtividade do Conselho Nacional de Desenvolvimento Científico e Tecnológico - CNPq. A. M. Soares Junior recebeu uma bolsa de pós-graduação da Coordenadoria de Aperfeiçoamento de Professores de Ensino Superior - CAPES. Esse trabalho constitui parte do trabalho de mestrado de A. M. Soares Junior. 